\title{
Molecular and clinical characterization of a small duplication Xp in a human female with psychiatric disorders
}

\author{
MARIA PICCIONE $^{1 *}$, CINZIA SANFILIPPO ${ }^{1}$, SIMONA CAVANI $^{2}$, PATRIZIA SALATIELLO $^{1}$, \\ MICHELA MALACARNE ${ }^{2}$, MAURO PIERLUIGI ${ }^{2}$, MARCO FICHERA ${ }^{2,3}$, DANIELA LUCIANO ${ }^{2,3}$ \\ and GIOVANNI CORSELLO ${ }^{1}$ \\ ${ }^{1}$ Dipartimento Materno Infantile, Università degli Studi, Via Alfonso Giordano 3, Palermo 90127, Italy \\ ${ }^{2}$ Laboratorio di Genetica, E.O. Ospedali Galliera, Via Alessandro Volta 10, Genova 16128, Italy \\ ${ }^{3}$ Laboratorio di Diagnosi Genetica IRCCS Oasi M. SS., Via Conte Ruggero 73, Tronia, Enna, Italy
}

[Piccione M., Sanfilippo C., Cavani S., Salatiello P., Malacarne M., Pierluigi M., Fichera M., Luciano D. and Corsello G. 2011 Molecular and clinical characterization of a small duplication Xp in a human female with psychiatric disorders. J. Genet. 90, 473-477]

\section{Introduction}

CGH techniques allow us to detect small duplications that occur in humans with phenotypic manifestations and demonstrate the importance of these duplications in the etiology of neurodevelopmental impairment. As in the case of other $\mathrm{X}$-linked disorders, $\mathrm{X}$-inactivation plays a major role in the clinical expression of such $\mathrm{X}$ chromosomal imbalances with usually milder symptoms in females than in males. Most male patients carrying Xp duplication have mental retardation (X-linked mental retardation) and variable facial dysmorphic features (Gimelli et al. 2002; Lugtenberg et al. 2006). Females with $\mathrm{Xp}$ duplications are usually protected from genetic imbalance by the inactivation of their abnormal $\mathrm{X}$ chromosome. Thus, preferential inactivation of the abnormal X chromosome in females leads to a normal phenotype, and it has been observed in the majority of these females (Matsuo et al. 1999). In this study, we present a case with the smallest duplication of Xp described to date, associated with development delay, psychiatric manifestations and random $\mathrm{X}$ inactivation in a human female. $\mathrm{CGH}$ array showed a $6-\mathrm{Mb}$ duplication, extending from Xp22.11 to Xp21.2. The molecular characterization of such a small duplication might help us to understand genotype-phenotype correlations in patients with partial duplication of Xp.

\section{Materials and methods}

\section{Case report}

The proband was born at term to healthy and nonconsanguineous parents, from an uneventful pregnancy. At birth her

*For correspondence. E-mail: piccionemaria@libero.it. weight was $3.1 \mathrm{~kg}$, the gestational age was unknown. The mother referred two previous abortions within 24th gestational weeks. At 2 years of age, the patient suffered from respiratory insufficiency and epiglottitis. Electroencephalogram (EEG) examination at 2 years was normal. Motor milestones were reached normally, but she had reduced cognitive capacity, language disorder and physical hyperactivity since infancy. When she was 7 years old, echocardiogram showed mitral valve insufficiency. Evaluated when she was 10 years old, her weight was $25.3 \mathrm{~kg}$ (10th percentile), her height was $132.2 \mathrm{~cm}$ (25th percentile), her head circumference was $51.8 \mathrm{~cm}$ (25th percentile). Her 11- and 6-year-old brothers were clinically normal. Ligament hyperlaxity, hypertelorism, flat nasal bridge, micrognatia, large and posteriorly rotated ears were also observed (figure 1). Neurological examination showed mild mental retardation, hyperactivity, language disorder and cognitive deficits. EEG examination was normal. Abdominal ultrasound did not show abnormalities. Psychological counselling was carried out and, although not diagnosed as psychotic, she showed aggressive behaviour problems and disorganization of thought process (prepsychotic phase). She started therapy with levomepromazine with good response to medication.

\section{Fluorescent in situ hybridization}

Single copy DNA probe of chromosome Xp, cloned in BAC, was obtained from Resources for Human Molecular Cytogenetics (http://www.biologia.uniba.it/rmc/). FISH procedure was performed as described by Cremer and Lichter (1992). Slides were counterstained with 4',6-diamidino-2phenylindole (DAPI) $(200 \mathrm{ng} / \mathrm{mL})$ and analysed by fluorescence microscope Olympus BX70 equipped with a cooled CCD Video Camera Image Point, Photometrics (Olympus,

Keywords. functional Xp disomy; array $\mathrm{CGH}$; psychiatric disorders; human genetics. 


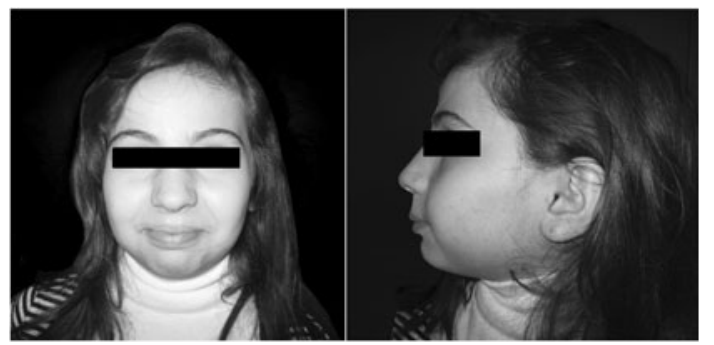

Figure 1. Front view and profile of the patient: hypertelorism, flat nasal bridge, micrognatia, large and posteriorly rotated ears.

Center Valley, USA). Image analysis was carried out with CytoVision software version 3.93.2 (Applied Imaging/PSI, Santa Clara, USA).

\section{CGH array}

DNAs of proband and control were extracted with Puregene DNA Isolation kit (Qiagen, Milan, Italy) according to the manufacturer's instructions. $\mathrm{CGH}$-array analysis was performed using a Human Genome CGH Microarray kit $4 \times$ 44 K (Agilent Technologies, Santa Clara, USA) with a resolution of $200 \mathrm{~kb}$ according to the manufacturer's instructions. Array slides were analysed with a Agilent G2505B scanner. Image analysis was carried out with Feature Extraction 9.5.1 (Agilent) and results visualized with CGH Analytics 3.4.40 (Agilent)

\section{Analysis by microsatellites}

To reveal the parental origin of de novo chromosome duplication Xp21.2, we carried out a gene dosage analysis by microsatellite polymorphic markers on genomic DNA of the patient and his parents. Four STRs (DXS8027, DXS7102, DXS8065 and DXS9896) located inside the duplicated region were chosen from UCSC database (http://genome. ucsc.edu/cgi-bin/hgGateway). Primers sequences and PCR conditions are available on request. For each marker, $1 \mathrm{~mL}$ of PCR product was mixed with $20 \mu \mathrm{L}$ of formamide and $1 \mu \mathrm{L}$ of Genescan 350 ROX size standard (Applied Biosystems, Foster City, USA). The mixture was denatured at $90^{\circ} \mathrm{C}$
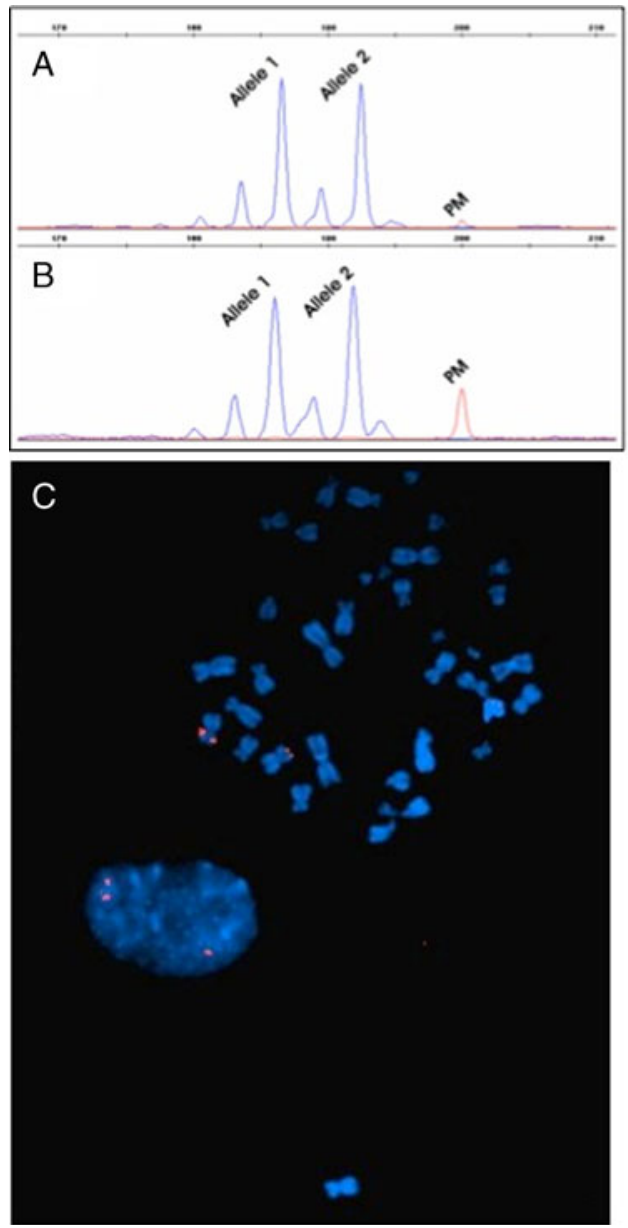

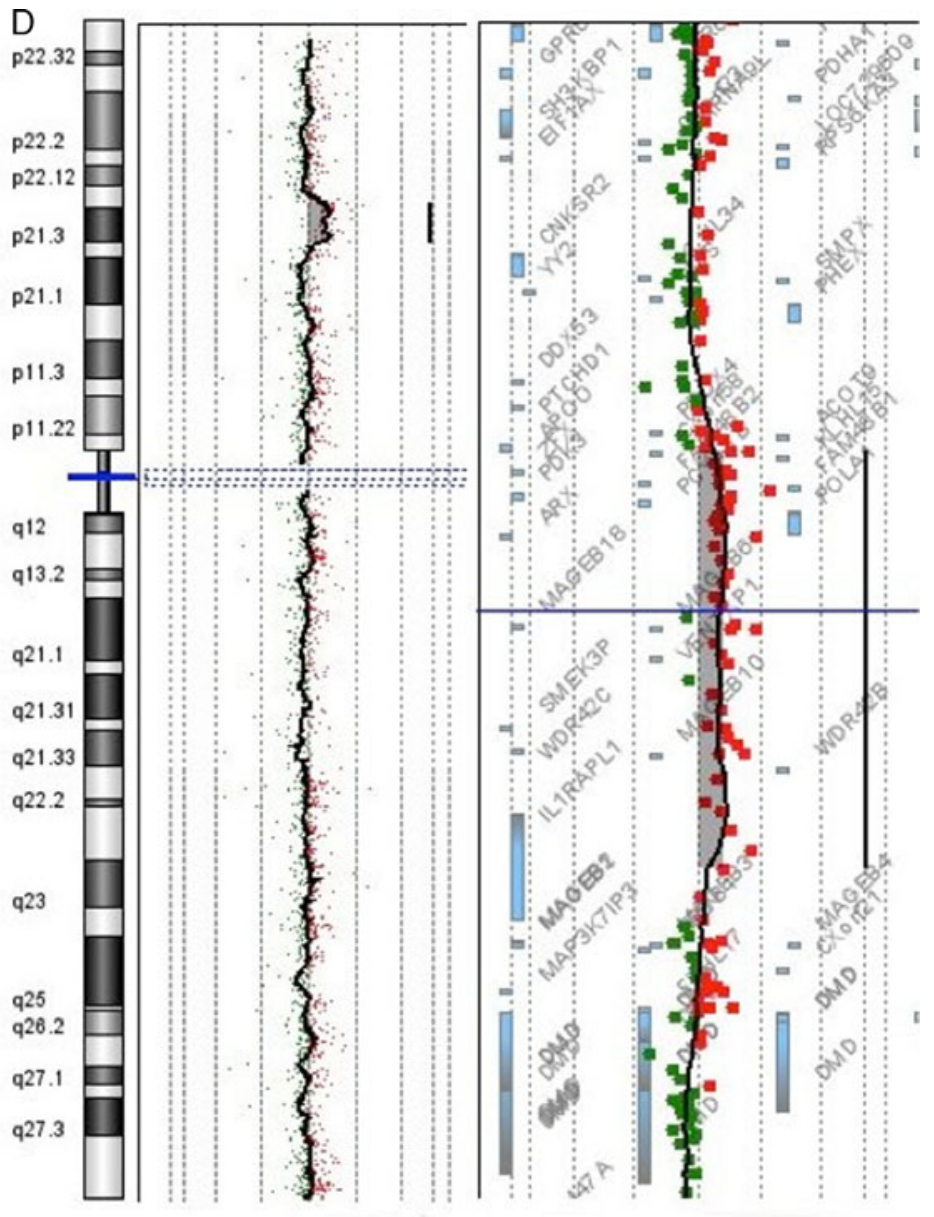

Figure 2. A-B, X-inactivation profile of the patient. A, electropherogram of PCR with primers for the methylated alleles. B, Electropherogram of PCR with primers for the unmethylated alleles. C, The RP11-399D20 (Xp21.3) BAC probe shows signals on the short arm of both $\mathrm{X}$ chromosomes. D, Genomewide array analysis of the proband showed a 6-Mb duplication at $\mathrm{Xp}[\operatorname{dup}(\mathrm{X})(\mathrm{p} 22.11 \mathrm{p} 21.2)]$, ranging from 23,604 to $29,661 \mathrm{Mb}$. 
for $2 \mathrm{~min}$. Capillary electrophoresis was performed using POP7 gel and ABI PRISM 3130 Genetic Analyser (Applied Biosystems). Fragment sizes and peak areas were determined by the GeneMapper software version 3.7. The analysis of gene dosage was conducted according to the method described by Di Bella et al. (2006).

\section{$X$-inactivation analysis}

The peripheral blood $\mathrm{X}$-inactivation pattern in proposita was determined at the human androgen receptor (HUMARA) locus using a methylation-specific PCR (M-PCR) method (Kubota et al. 1999). The PCR products and the genotyping marker Genescan-500 ROX size standard (Applied Biosystems) were separated on an ABI 3130 automated DNA sequencer and analysed with the GeneMapper analysis software (Applied Biosystems) for peak position and area intensity calculations.

\section{Results}

Genomewide array analysis of the proband showed a 6-Mb duplication at $\mathrm{Xp}(\operatorname{dup}(\mathrm{X})(\mathrm{p} 22.11 \mathrm{p} 21.2))$, ranging from 23,604 Mb to 29,661 Mb (figure 2D). This duplication harboured known 23 genes (figure 2D). The RP11-399D20 (Xp21.3) BAC probe showed signals only on the short arm of both $\mathrm{X}$ chromosomes, thus excluding a chromosomal insertion (figure $2 \mathrm{C}$ ).

FISH analysis on the proband and her parents confirmed the rearrangement (figure 2C), showing that it was de novo and that the duplication was of paternal origin. The $\mathrm{X}$-inactivation analysis showed a random $(50: 50)$ $\mathrm{X}$-inactivation pattern in proposita (figure 2, A-B).

\section{Discussion}

We report on a girl with a small partial de novo duplication of $\mathrm{Xp}$ associated with abnormal phenotype. The normal and the duplicated $\mathrm{X}$ chromosomes in the patient we described were randomly inactivated. Duplications involving the short arm of $\mathrm{X}$ chromosome are described in males associated with mental retardation and facial dysmorphic features. Case reports presenting duplication of Xp in females are rare because females carrying Xp duplication are usually protected by the inactivation of the chromosome which contains the duplication. The negative effects of $\mathrm{X}$ duplication are related to the size of the functional imbalance (Kolomietz et al. 2005). The present patient showed a small duplication detected with CGH-array, the smallest described to date, associated with mild dysmorphic features, mild mental retardation, cognitive deficits, language disorder and psychiatric problems. The duplication we report on harbours 23 known genes and, since there is no gross functional imbalance, we can speculate that the neurological impairments are probably caused by a dosage effect of one or more genes located within the duplicated region. X-linked MR is believed to be caused by alterations in molecular pathways that are important for cognitive functions and crucial for neuronal morphogenesis. The duplicated segment harbours two genes whose loss-of-function mutations have been associated with X linked mental retardation: ILIRAPLI(MRXlinked 21/34) and $A R X$ (Chiurazzi et al. 2008). Till date, no duplication of the entire genes $A R X$ and ILIRAPLI has been considered to be responsible for neurodevelopmental impairments. $A R X$ gene belongs to the family of Aristaless-related paired-class homeobox genes. Bienvenu et al. (2002) speculated that $A R X$ may act to regulate neuroepithelial cell proliferation and the timing of neuronal differentiation and that the mutation of the gene could affect the development of cognitive function. Mutation of $A R X$ gene is involved in X-linked mental retardation (Strømme et al. 2002), in isolated agenesis of the corpus callosum in females (Kato et al. 2004), and in learning difficulties in females without skewed $\mathrm{X}$ inactivation (Poirier et al. 2006). Recently, it has been shown that ARX is a transcription factor that participates in the development of GABAergic and cholinergic neurons in the forebrain (Kitamura et al. 2009). Missense, nonsense mutations and deletion/insertions of $A R X$ have been reported, associated with mental retardation and developmental delay (Nawara et al. 2008; Poirier et al. 2006; Troester et al. 2007). Malformation phenotypes are usually associated with protein truncation mutations and missense mutations in the homeobox; nonmalformation phenotypes, including X-linked infantile spasm are associated with missense mutations outside the homeobox and expansion of the polyA tracts (Ruggieri et al. 2010). The 24-bp duplication (c.428_452dup) is the most frequent pathogenic variation in $A R X$, associated with intellectual disability (Demos et al. 2009).

IL1RAPL1 gene encodes for a member of the interleukin 1 receptor family protein and it is expressed at a high level in post-natal brain structures involved in the hippocampal memory system, which suggests a specialized role in the physiological processes underlying memory and learning abilities. Carrié et al. (1999) demonstrated the importance of interleukin signalling pathways in cognitive functions by studying the effects of disruption in the expression of genes located within the Xp22.1-21.3 region. The authors found that deletions and a nonsense mutation in this gene were responsible for cognitive impairment in patients carrying the disruption. IL1RAPL1 has been shown to interact with the neuronal calcium sensor-1 protein (NCS-1), a protein widely expressed in neurons, and to regulate N-type $\mathrm{Ca} 2$ channel and neurite elongation (Gambino et al. 2007). Mutations in the calcium-related IL1RAPL1 gene are also associated with autism in both females and males (Piton et al. 2008). Females with a loss-of-function mutation in ILIRAPL1 were found to exhibit a spectrum of phenotypes ranging from no obvious impairment to autism with or without mild mental retardation. To date, no cases of ILIRAPL1 duplication have been associated with cognitive and learning difficulties in males and females. Thorson et al. (2010) presented 
a female patient with moderate expressive language delay caused by an interstitial duplication of Xp21-p22. The duplicated region harbours several genes involved in X-linked mental retardation $(C D K L 5, N H S$ and $A R X)$ and the duplication is responsible for the interruption of the upstream portion of the ILIRAPLI gene, causing the inactivation of the partially duplicated allele. It has been shown that inactivation of IL1RAPL1 gene can result in cognitive delays (Nawara et al. 2008), but, according to the findings of our case report, we can speculate that both increased or decreased expression of dosage sensitive genes can disrupt normal function and development of CNS.

The phenotype of our patient is mild compared to previous reported cases, where the duplicated segments were longer. Some of the dysmorphic features of our case report overlap with clinical signs described in literature: hypertelorism (Telvi et al. 1996; Matsuo et al. 1999), flat nasal bridge (Thorson et al. 2010), micrognatia (Gimelli et al. 2002), large and posterior rotated ears (Matsuo et al. 1999). However, the more frequent findings of microcephaly, hypotonia and skeletal anomalies (Matsuo et al. 1999; Telvi et al. 1996; Thorson et al. 2010) were not found in our case; this is probably due to the size of the duplicated segment which harbours only 23 known genes, which are probably responsible for few dysmorphic signs. The comparison with previously reported patients is difficult because only a few phenotypically abnormal cases of small $\mathrm{X}$ chromosome duplication detected by CGH-Array have been described so far. Most cases reported with duplication of Xp carried large genomic imbalance and molecular characterization has not always been performed. It is not clear which of the genes involved in the duplication are relevant to the phenotype and to the neurological disorders of our patient. Two of the 23 genes involved have been associated with XLMR and we can suppose that the overexpression of such genes could lead to the language impairments and to the psychiatric disorders that our patient presents. It is possible that $A R X$ duplication is responsible for the developmental impairments of our patient, or that the ILIRAPLI/NSC-1 interaction can be affected either by lack of expression or by ILIRAPL1 functional disomy. We cannot exclude that gene disruption at duplication breakpoints, or position effects may have caused the phenotypical features. Descriptions of additional patients with small Xp duplications are needed to better correlate genotype and phenotype.

\section{Acknowledgement}

The authors wish to thank the patient and her family for participating in this study.

\section{References}

Bienvenu T., Poirier K., Friocourt G., Bahi N., Beaumont D., Fauchereau F. et al. 2002 ARX, a novel Prd-class-homeobox gene highly expressed in the telencephalon, is mutated in Xlinked mental retardation. Hum. Mol. Genet. 11, 981-991.
Carrié A., Jun L., Bienvenu T., Vinet M. C., McDonell N., Couvert P. et al. 1999 A new member of the IL-1 receptor family highly expressed in hippocampus and involved in X-linked mental retardation. Nat. Genet. 23, 25-31.

Chiurazzi P., Schwartz C. E., Gecz J. and Neri G. 2008 XLMR genes: update. Eur. J. Hum. Genet. 16, 422-434.

Cremer T. and Lichter P. 1992 Chromosome analysis by nonisotopic in situ hybridization. Human cytogenetics - a practical approach, pp. 157-192. IRL Press, New York, USA.

Demos M. K., Fullston T., Partington M. W., Gécz J. and Gibson W. T. 2009 Clinical study of two brothers with a novel 33 bp duplication in the ARX gene. Am. J. Med. Genet. A. 149, 14821486.

Di Bella M. A., Calì F., Seidita G., Mirisola M., Ragusa A., Ragalmuto A. et al. 2006 Screening of subtelomeric rearrangements in autistic disorder: identification of a partial trisomy of $13 \mathrm{q} 34$ in a patient bearing a $13 \mathrm{q} ; 21 \mathrm{p}$ translocation. Am. J. Med. Genet. B 141, 584-590.

Gambino F., Pavlowsky A., Béglé A., Dupont J. L., Bahi N., Courjaret R. et al. 2007 IL1-receptor accessory protein-like 1 (IL1RAPL1), a protein involved in cognitive functions, regulates N-type Ca2+-channel and neurite elongation. Proc. Natl. Acad. Sci. USA 104, 9063-9068.

Gimelli G., Giglio S., Zuffardi O., Alhonen L., Suppola S., Cusano R. et al. 2002 Gene dosage of the spermidine/spermine N(1)acetyltransferase (SSAT) gene with putrescine accumulation in a patient with a Xp21.1p22.12 duplication and keratosis follicularis spinulosa decalvans (KFSD). Hum. Genet. 111, 235-241.

Kato M., Das S., Petras K., Kitamura K., Morohashi K., Abuelo D. N. et al. 2004 Mutations of ARX are associated with striking pleiotropy and consistent genotype-phenotype correlation. Hum. Mutat. 23, 147-159.

Kitamura K., Itou Y., Yanazawa M., Ohsawa M., Suzuki-Migishima R., Umeki Y. et al. 2009 Three human ARX mutations cause the lissencephaly-like and mental retardation with epilepsy-like pleiotropic phenotypes in mice. Hum. Mol. Genet. 18, 37083724.

Kolomietz E., Godbole K., Winsor E. J., Stockley T., Seaward G. and Chitayat D. 2005 Functional disomy of Xp: prenatal findings and postnatal outcome. Am. J. Med. Genet. A. 134, 393398.

Kubota T., Nonoyama S., Tonoki H., Masuno M., Imaizumi K., Kojima M. et al. 1999 A new assay for the analysis of Xchromosome inactivation based on methylation-specific PCR. Hum. Genet. 104, 49-55.

Lugtenberg D., de Brouwer A. P., Kleefstra T., Oudakker A. R., Frints S. G., Schrander-Stumpel C. T. et al. 2006 Chromosomal copy number changes in patients with non-syndromic X linked mental retardation detected by array CGH. J. Med. Genet. 43, 362-370.

Matsuo M., Muroya K., Kosaki K., Ishii T., Fukushima Y., Anzo M. et al. 1999 Random X-inactivation in a girl with duplication Xp11.21-p21.3: report of a patient and review of the literature. Am. J. Med. Genet. 86, 44-50.

Nawara M., Klapecki J., Borg K., Jurek M., Moreno S., Tryfon J. et al. 2008 Novel mutation of IL1RAPL1 gene in a nonspecific X-linked mental retardation (MRX) family. Am. J. Med. Genet. A. 146, 3167-3172.

Piton A., Michaud J. L., Peng H., Aradhya S., Gauthier J., Mottron L. et al. 2008 Mutations in the calcium-related gene IL1RAPL1 are associated with autism. Hum. Mol. Genet. 17, 3965-3974.

Poirier K., Lacombe D., Gilbert-Dussardier B., Raynaud M., Desportes V., de Brouwer A. P. et al. 2006 Screening of ARX in mental retardation families: Consequences for the strategy of molecular diagnosis. Neurogenetics 7, 39-46.

Ruggieri M., Pavone P., Scapagnini G., Romeo L., Lombardo I., Li Volti G. et al. 2010 The aristaless (Arx) gene: one gene for 
many "interneuronopathies". Front. Biosci. (Elite. Ed.) 2, 701710.

Strømme P., Mangelsdorf M. E., Shaw M. A., Lower K. M., Lewis S. M., Bruyere H. et al. 2002 Mutations in the human ortholog of Aristaless cause X-linked mental retardation and epilepsy. Nat. Genet. 30, 441-445.

Telvi L., Ion A., Carel J. C., Desguerre I., Piraud M., Boutin A. M. et al. 1996 A duplication of distal Xp associated with hypogonadotrophic hypogonadism, hypoplastic external genitalia, men- tal retardation, and multiple congenital abnormalities. J. Med. Genet. 33, 767-771.

Thorson L., Bryke C., Rice G., Artzer A., Schilz C., Israel J. et al. 2010 Clinical and molecular characterization of overlapping interstitial Xp21-p22 duplications in two unrelated individuals. Am. J. Med. Genet. A. 152, 904-915.

Troester M. M., Trachtenberg T. and Narayanan V. 2007 A novel mutation of the $A R X$ gene in a male with nonsyndromic mental retardation. J. Child Neurol. 22, 744-748.

Received 7 November 2010, in final revised form 9 May 2011; accepted 17 May 2011

Published on the Web: 4 November 2011 